\title{
Experimental study of the turbulent structure of the surface marine Atmospheric Boundary Layer over the Aegean Pelagos under etesian winds
}

\author{
Kostopoulos V.E. , Helmis C.G., Raptis P.I. \\ Department of Environmental Physics and Meteorology, Faculty of Physics, University of \\ Athens, University Campus, Zografou, 15784, Athens, Greece \\ *corresponding author e-mail: vkostopoulos@phys.uoa.gr
}

\begin{abstract}
In order to study the physical processes of the turbulent transportation of mass and energy within the surface Marine Atmospheric Boundary Layer over the Aegean Pelagos, field measurements were conducted on the island of Skyros, mainly under the etesian winds, during summer 2011. A meteorological mast was installed close to the shoreline, instrumented with fast anemometer (sonic) and hydrometer measuring the three components of the wind, the virtual temperature and water vapor at $10 \mathrm{~m}$ height with a sampling frequency of $20 \mathrm{~Hz}$. At the same mast slow response sensors were measuring wind speed and direction, temperature and humidity at three levels $(2,6$ and $10 \mathrm{~m})$. Weak stable to near neutral flows were recorded during the experimental period. The eddy correlation analysis revealed the momentum and heat fluxes values which are presented and discussed. The estimated values are related both with stability and wind speed variations.
\end{abstract}

\section{Introduction}

The atmospheric surface layer is the layer within the Marine Atmospheric Boundary Layer (MABL) where significant exchanges of energy, momentum and mass occur with impact on the atmospheric and maritime circulations, in a whole spectrum of time and spatial scales. The fundamental importance of understanding the structure and the characteristics of the MABL has forced scientific expeditions over the last decades, mostly at open seas and oceans (Smith et al. 1996). Such experiments are still today considered compulsory in climate predictions since they provide modellers with essential parameterization schemes for surface turbu- 
lent fluxes of momentum, heat and water vapor (Brunke et al. 2003). Wind stress is usually parameterized in terms of drag coefficient $\left(C_{D}\right)$, which is defined

$$
C_{D}=\frac{\tau}{\rho \cdot U^{2}},
$$

where $\tau$ is the wind stress at the sea surface, $\rho$ is the air density -and $U$ is the mean wind speed at a reference height $(10 \mathrm{~m})$. The choice of using the drag coefficient regression equation under neutral conditions is regionally dependent (Geernaert and Plant 1990), while recent studies underline the need of improved surface fluxes parameterization (Edson et al. 2007). Short fetched flows wind stress is documented greater over young and developing wave fields compared to older wave fields, which are in more equilibrium with the wind. Since developing waves occur with atmospheric flow acceleration and fetch limited off-shore flow, it is expected that over the Aegean where complex topography and special oceanographic features exist, enhanced values of the momentum flux will be measured responding to air-sea interaction in much smaller spatial $\left(10^{2} \mathrm{~km}\right)$ and time scales comparing to the oceans (Sofianos et al. 2002).

It is worth mentioning that there are no published measurements over the semi closed sea of Aegean Pelagos up to now, while two expeditions in the Mediterranean Sea were reported, regarding mostly momentum flux response to regional sea state conditions (Drennan et al. 2003). Also the majority of past experiments took place on board ship platforms and it has been proved that such measurements suffer from various errors in flux measurements as well as from dependencies on assumptions of the applied methods (Frederickson et al. 1997). On the other hand, by measuring the marine ABL from land, the eddy correlation analysis can be utilised but the formation of the internal boundary layer should be taken under consideration.

The purpose of this work is to present the conducted experiment as well as the analysis of first results regarding the vertical transport of momentum and heat in relation with the atmospheric stability and the wind speed variations.

\section{Experimental area and instrumentation}

The island of Skyros of the Aegean Pelagos, hosted the experimental campaign which lasted two weeks, starting from the end of August 2011, under mainly etesian wind flows. This island is located at the centre of the Aegean Sea, is mountainous and at the north side a well distinguished prominence of $400 \mathrm{~m}$ height exists, covered by dense forests, followed by an almost leveled terrain with low hills (Fig. 1). The experimental site was located at the north-eastern part, an area of more than $1 \mathrm{~km}^{2}$ with mean altitude less than $10 \mathrm{~m}$, which expands to the sea surrounded mostly from shoreline with gentle slope and at a distance of several hundred meters to few kilometers from the ground elevation. The presence of three 
small reefs located few hundred meters off shore, is considered to create internal boundary layer (IBL) under certain wind directions.

A three dimensional sonic anemometer (R3-50) and a fast hydrometer ( $\mathrm{Li}$ 7500 ) measuring, with a sampling frequency of $20 \mathrm{~Hz}$, the three components of the wind, virtual temperature, water vapour pressure and $\mathrm{CO}_{2}$, were placed at $10 \mathrm{~m}$ height on a meteorological mast that was installed at $30 \mathrm{~m}$ distance from the shoreline. The mast was instrumented also with slow response sensors $(1 \mathrm{~Hz} \mathrm{sam}-$ pling frequency) at three levels $(2,6$ and $10 \mathrm{~m})$ measuring wind speed and direction, temperature and relative humidity. The selection of the mast location was based on the fact that the developed IBL, at a distance of $30 \mathrm{~m}$ from the shoreline, will be characterized with heights much less than $10 \mathrm{~m}$ (Savelyev et al. 2004). Additional analysis was conducted in order to include only cases of pure marine $\mathrm{ABL}$ using certain wind directions of open sea.

More than one hundred hours of open sea MABL flow data were recorded. Data was treated with quality control procedures proposed by the international literature (Lee et al. 2002) and subsets of data which were not characterized as pure marine data were excluded. Several records where identified as instrumentation problems mostly related with the water vapour caused probably by the sea spray. Tilt corrections were also applied using the planar fit method (Wilczak et al. 2001) and all records were furthermore examined for stationarity using the criterion suggested by Mahrt et al. (1996).

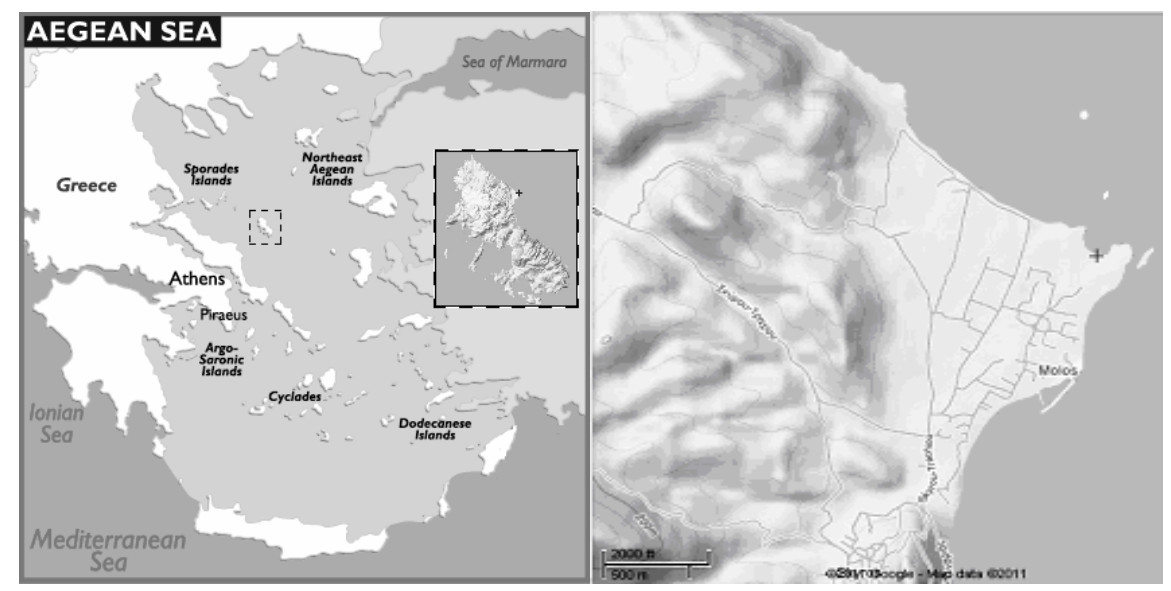

Fig. 1. The Aegean Pelagos and the island of Skyros (left). The location of the experimental site indicated by cross, at the north eastern part of the island (right). 


\section{Flux measurements under Etesian winds over the Aegean Sea}

The etesian winds are seasonal winds, caused by the interaction of the thermal low of India and the high pressure field of the Azores or even by the dominance of one of them. They start from June and last until October and their sequence and intensity increase and maintain high levels until the middle of September, when they start to decay. In general they blow from north to northeast directions and their highest intensities occur during daytime while at night the wind speed usually decreases. Moderate to strong etesian winds were recorded during the experimental period, ranging up to $12 \mathrm{~m} / \mathrm{s}$ while temperature fluctuated from $25^{\circ} \mathrm{C}$ to $31^{\circ} \mathrm{C}$ and relative humidity from $50 \%$ to $85 \%$. During the experimental period the sky was cloudless, apart from small mountain induced clouds at the south part of the island.

Eddy correlation analysis revealed momentum flux values ranged up to 0.2 $\mathrm{m}^{2} / \mathrm{sec}^{2}$ increasing with the wind over the entire wind speed range (as shown in Fig. 2), which are close to the ones found over open sea (Helmis et al. 2006, Large and Pond 1981). The highest momentum flux values appear under neutral conditions, decreasing rapidly with stability reaching values of the order of $0.01 \mathrm{~m}^{2} / \mathrm{s}^{2}$.
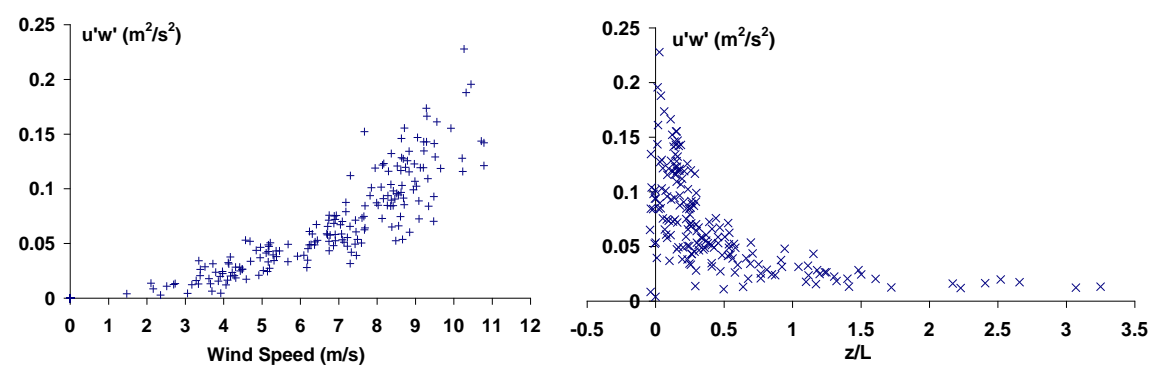

Fig. 2. Momentum flux towards wind speed and stability. Neutral conditions are considered for $\mathrm{z} / \mathrm{L}<|0.02|$.
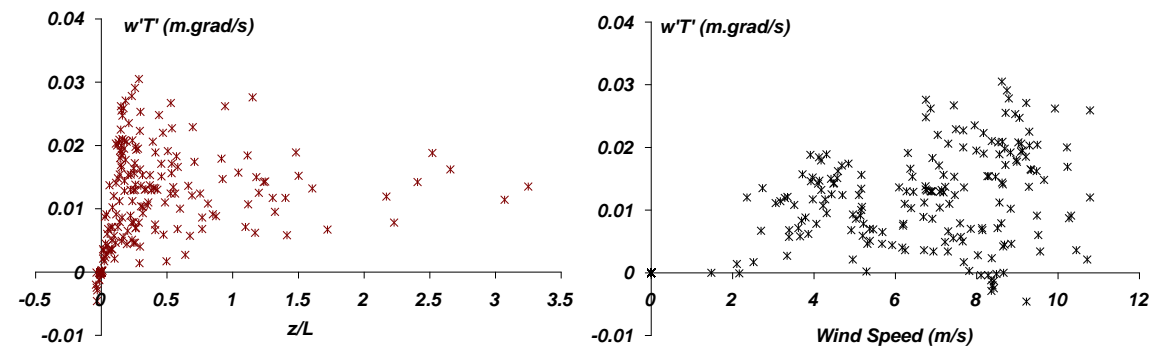

Fig. 3. Heat flux towards stability and wind speed

Heat flux values are very small for neutral cases as expected (as shown in Fig. 3 ), while enhanced values appear mainly under slightly stable conditions, increas- 
ing with the increment of wind speed. Turbulent fluxes are generally expected to decrease under very stable conditions, reflecting the insufficient generation of turbulence needed to overcome the absorption of energy by buoyant forces. The maintained relatively high values of heat transport at stronger stability $(\mathrm{z} / \mathrm{L}>1)$ shown in figure 3 , belong to light wind speed cases (less than $4 \mathrm{~m} / \mathrm{s}$ ) where dynamic processes are thought to be strongly modulated or even driven by thermal forcing (Edson et al. 2004).

In figure 4 , the drag coefficient $\left(C_{d}\right)$ gives high values at very low winds $(<2.5 \mathrm{~m} / \mathrm{s})$ which might be attributed to viscosity effects even though the presented large scatter reflects the uncertainty of it's calculation caused by large random flux errors and the sensitivity on the method of calculation of the stress. At stronger winds when sea surface gradually shifts from aerodynamic smooth to rough, the values tend to enhance as expected (Edson et al. 2007).

Additional analysis will provide further insight to the physical processes as well as to the influence of the various meteorological factors to the turbulent transport of fluxes.

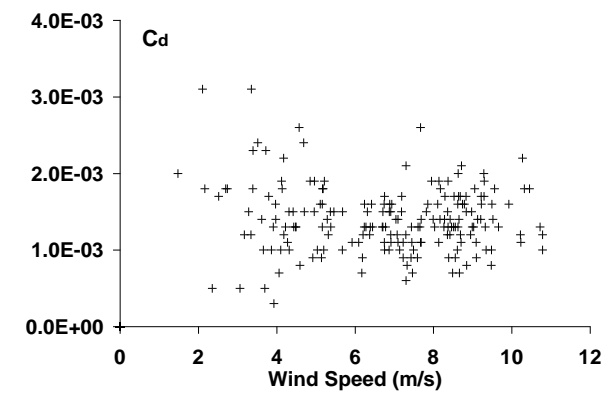

Fig. 4. Drag coefficient towards wind speed.

\section{Conclusions}

Micrometeorological measurements of the marine ABL were recorded under etesian winds. The results of this campaign reveal momentum flux values at the surface marine $\mathrm{ABL}$, of the same order that were measured over ocean for the wind speed range recorded during this campaign. The turbulent fluxes are shown to increase with wind speed and are depended on the stability. High values of heat fluxes under light wind speed and stable conditions might reflect thermally driven dynamical processes.

Further research is needed towards the understanding of the physical processes related with the vertical transport of momentum, heat and humidity within the surface marine $\mathrm{ABL}$ of the Aegean sea. 
Acknowledgments This research has been co-financed by the European Union (European Social Fund - ESF) and Greek national funds through the Operational Program "Education and Lifelong Learning" of the National Strategic Reference Framework (NSRF) - Research Funding Program: Heracleitus II, Investing in knowledge society through the European Social Fund. The authors also gratefully acknowledge Dr. Halios C., Dr. Sgouros G. and Arnaoutis S., for their contribution in the frame of this work.

\section{References}

Brunke MA, Fairall CW, Zeng X, Eymard L, Curry JA (2003) Which Bulk Aerodynamic Algorithms are Least Problematic in Computing Ocean Surface Turbulent Fluxes?. J Clim 16:619-635. doi:10.1175/1520-0442(2003)016<0619:WBAAAL >2.0.CO;2

Drennan WM, Graber HC, Hauser D, Quentin C (2003) On the wave age dependence of wind stress over pure wind seas. J Geophys Res 108:1-13. doi: 10.1029/2000JC000715

Edson J et al (2007) The Coupled Boundary Layers and Air-Sea Transfer Experiment in Low Winds (CBLAST-LOW). Bull Am. Meteorol Soc 88:341-356. doi:10.1175/BAMS-88-3-341

Edson J, Crofoot R, McGillis W, Zappa C (2004) Investigations of flux-profile relationships in the marine atmospheric surface layer during CBLAST. 16th Symposium on Boundary Layers and Turbulence, Portland, ME.

Frederickson PA, Davidson KL, Edson JB (1997) A Study of Wind Stress Determination Methods from a Ship and an Offshore Tower. J Atmos Ocean Technol 14:822-834. doi:10.1175/1520-0426(1997)014<0822:ASOWSD>2.0.CO;2

Geernaert GL, Plant WJ (1990) Surface Waves and Fluxes: Current theory, Kluwer, Netherlands

Helmis CG, Wang G, Katsouvas G, Gao Z, Halios CH, Kalogiros JA, Wang S, Sgouros G, Edson $J$ (2006) On the turbulent structure of the marine atmospheric boundary layer from CBLAST Nantucket measurements. Global Nest J 8: 210-217.

Large WG, Pond S (1980) Open sea momentum flux measurements in moderate to strong winds. J Phys Oceangr 11:324-336, doi: http://dx.doi.org/10.1175/15200485(1981)011<0324:OOMFMI>2.0.CO;2

Lee X et al (2002) Handbook of Micrometeorology: A Guide for Surface Flux Measurement and Analysis, Kluwer, Dordrecht

Mahrt L, Vickers D, Howell J, Hojstrup J, Wilczak JM, Edson J, Hare J (1996) Sea surface drag coefficients in the Riso Air Sea Experiment. J Geophys 101:14327-14335. doi:10.1029/96JC00748

Savelyev S, Taylor P (2004) Internal Boundary Layers: I. Height Formulae for Neutral and Diabatic Flows. Bound Layer Meteorol 115:1-25. doi: 10.1007/s10546-004-2122-Z

Smith SD, Fairall CW, Geernaert GL, Hasse L (1996) Air-sea fluxes: 25 years of progress. Bound Layer Meteorol 78:247-290. doi: 10.1007/BF00120938

Sofianos S, Johns W, Lascaratos A, Murray S, Olson D, Theocharis A (2002) Draft Report of the Aegean Sea Workshop. http://www.oc.phys.uoa.gr/workshop/Aegean_Draft_Report_f.htm

Wilczak JM, Oncley SP, Stage SA (2001) Sonic anemometer tilt correction algorithms. Bound Layer Meteorol 99:127-150. doi:10.1023/A:1018966204465 